\title{
Correlating Hard-Braking Activity with Crash Occurrences on Interstate Construction Projects in Indiana
}

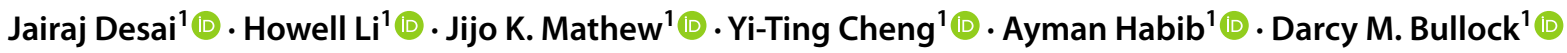

Received: 4 August 2020 / Revised: 23 October 2020 / Accepted: 27 October 2020 / Published online: 16 November 2020

(c) The Author(s) 2020

\begin{abstract}
The Federal Highway Administration (FHWA) reported between 2016 and 2017, fatal crashes in work zones increased by $3 \%$, while fatal crashes outside of work zones decreased by $1.5 \%$. The FHWA also reported that work zones account for approximately $10 \%$ of the nation's overall congestion and $24 \%$ of unexpected interstate delays. This paper reports on a study of 23 construction work zones that covered approximately 150 centerline miles of Indiana interstate roadway in the summer of 2019. Approximately 50\% of all interstate crashes for the period of May to September 2019 occurred within or in an approach upstream or downstream of one of these work zones. Commercially available vehicle hard-braking event data is used for the study and geofenced to the work zone approaches and limits. This research examined 196,215 hard-braking events over a 2-month period in the summer of 2019 and 3132 crashes over the same 2-month period in 2018 and 2019 for the 23 interstate work zones. The study found there were approximately $1 \mathrm{crash} / \mathrm{mile}$ for every 147 hard-braking events in and around a construction site. The $R^{2}$ was approximately 0.85 . The paper concludes by recommending that hard-braking event data be used by agencies to quickly identify emerging work zone locations that show relatively large number of hardbraking events for further evaluation.
\end{abstract}

Keywords Braking $\cdot$ Crash rate $\cdot$ Highway safety $\cdot$ Vehicle probe data

\section{Introduction}

\section{Motivation}

There are approximately 800 fatal work zone crashes in the US annually, most of which occur in the summer and fall, and over $25 \%$ of those crashes involve large trucks or

Jairaj Desai

desaij@purdue.edu

Howell Li

howell-li@purdue.edu

Jijo K. Mathew

kjijo@purdue.edu

Yi-Ting Cheng

cheng331@purdue.edu

Ayman Habib

ahabib@purdue.edu

Darcy M. Bullock

darcy@purdue.edu

1 Joint Transportation Research Program, Purdue University, West Lafayette, IN, USA buses (FHWA, 2018). The Federal Highway Administration (FHWA) reported between 2016 and 2017 (FHWA, 2018) fatal crashes in work zones increased by $3 \%$, while fatal crashes outside of work zones decreased by $1.5 \%$. The FHWA also reported that work zones account for approximately $10 \%$ of the nation's overall congestion and $24 \%$ of unexpected interstate delays (FHWA 2018). Historically, crash report data has been used to identify opportunities to improve the design of future construction zones. However, the infrequency of crashes and the time it takes for personnel to read crash narratives makes it difficult and infeasible to use crash data for tactical monitoring of work zones. Furthermore, crash reports are often reported with a time delay due to associated investigation time, and the exact location and time reported in the crash reports varies by investigating agency. In contrast, hard-braking event data can be obtained daily from commercial providers with a precise timestamp and geo-location information. This paper investigates the feasibility of using hard-braking event data to identify opportunities to improve the safety and operating efficiency of construction work zones. 


\section{Literature Review}

Work zone safety and mobility have been measured in the past using a variety of metrics, including number of injury crashes, motorist complaints, safety inspection scores, closure, and delay times (Ullman et al. 2011) and crash severity indexes (Li and Bai 2008). Probe vehicle data has been effectively leveraged to measure travel time delays in work zones and establish correlations among crashes and queue times (Haseman et al. 2010; M. Mekker et al. 2018a, b). However, crashes are often reported with a time lag and underreported due to a variety of reasons (Janstrup et al. 2016; Tarko 2019; Yamamoto et al. 2008), including unwillingness of involved drivers to report a crash (Blincoe et al. 2002), or reporting delays due to ongoing investigations that may lead to a change in the documented crash severity. This can potentially hamper or render unreliable any near real-time measurement of safety performance in work zones. Moreover, not all locations with safety challenges have crashes early in the construction season to help identify problem areas. Drivers making evasive maneuvers to avoid conflicts, such as decelerating in advance of stopped traffic, have been well studied and modeled (Davis et al. 2011; Tarko 2012). Finding a way to detect near-misses before crashes accumulate can be useful to proactively develop operating strategies.

Multiple studies in the past have analyzed braking behavior and reaction times at the individual driver level in a variety of hazardous driving situations. Using simulated driving environments, hard-braking by distracted motorists was found to have significant impacts on following vehicles in traffic, increasing the risk of a rear-end collision (Haque and Washington 2015). Investigations into the use of harsh braking incidents as a surrogate for truck crash counts using truck telematics data have shown promise in identifying potential hot spots with high crash risk (Kamla et al. 2019). A 6-month study of drivers in Georgia traveling on freeways, arterials, and local roads found that those involved in a crash incident tend to more frequently hard brake $\left(8.8 \mathrm{ft} / \mathrm{s}^{2}\right)$ than those not involved in crashes (Jun et al. 2007). An analysis of undesirable driving events such as hard braking, sharp turning and sudden lane changes showed that looking at the frequency of occurrence of such events could prove to be a valuable surrogate for determining driver behavior and accident risk (Musicant et al. 2010). Others have reported the linkages between hard-braking and driver performance, crash severity and driver fatigue (Kiefer et al. 2005; Mollicone et al. 2019). Although the existing literature has focused on driver behavior and its correlation to crash risk, we propose using aggregate hard-braking event counts as a surrogate safety measure instead of crash counts, for transportation system elements. Although this study focuses on hardbraking activity within work zones on interstate roadways, the relationship established here between hard-braking and crash incident counts encourages future research into using hard-braking as a surrogate safety measure for other elements of transportation systems as well (arterials, local roads, roundabouts).

\section{Enhanced Probe Data}

Commercial probe data that provides real-time average segment speeds every minute at approximately 1-mile fidelity has been available for several years. In fact, in Indiana, the state ingests approximately 32 billion records per year and uses that data for a number of historical and real-time dashboards (Day et al. 2016).

Enhanced probe data that contains vehicle acceleration attributes has become available in the past 2 years. One example of enhanced probe data generated by anonymized passenger vehicles includes the time and the latitude and longitude attribute of a hard-braking event experienced with a deceleration greater than $8.76 \mathrm{ft} / \mathrm{s}^{2}$ (defined by original equipment manufacturer). As a surrogate safety measure, and when considered in aggregate form, hard-braking activity has the potential to provide timely information to agencies in evaluating the safety performance of a work zone by quantifying near-misses. However, there are no reports in existing literature of agencies using information such as hard-braking for operation-oriented management of roadways.

\section{Objectives}

The objectives of this study are:

1) To evaluate the relationship between hard-braking activity and crashes in and around Interstate construction projects in Indiana

2) To investigate causal factors for increased hard-braking activity

\section{Data Description}

\section{Study Locations}

The study evaluated 23 construction zones spanning 6 different interstate routes across the state of Indiana. Construction on these work zones was carried out in the summer of 2019, however crash incidents in these zones were recorded for 2018 as well as 2019 for comparing the impact of construction activity on crash frequency. Table 1 summarizes the approach start and end mile markers (MM) for each of these 
Table 1 Summary details and crash counts for areas studied from July 1 to August 31 for 2018 and 2019

\begin{tabular}{|c|c|c|c|c|c|c|}
\hline \multirow[t]{2}{*}{ Work Zone } & \multirow[t]{2}{*}{ Route } & \multirow[t]{2}{*}{ Approach Start MM } & \multirow{2}{*}{$\begin{array}{l}\text { Approach } \\
\text { End MM }\end{array}$} & \multicolumn{2}{|c|}{ July and August } & \multirow[t]{2}{*}{$\%$ Change } \\
\hline & & & & 2018 Crashes & 2019 Crashes & \\
\hline Z01 & $\mathrm{I}-65$ & 170 & 183 & 32 & 32 & $0 \%$ \\
\hline Z02 & $\mathrm{I}-74$ & 27 & 45 & 13 & 9 & $-31 \%$ \\
\hline Z03 & $\mathrm{I}-70$ & 1 & 11 & 16 & 17 & $6 \%$ \\
\hline Z04 & $\mathrm{I}-70$ & $29-41 \& 43-55$ & & 25 & 23 & $-8 \%$ \\
\hline Z05 & $\mathrm{I}-69$ & 259 & 275 & 14 & 30 & $114 \%$ \\
\hline Z06 & I-69 & 326 & 347 & 26 & 30 & $15 \%$ \\
\hline Z07 & I-69 & 214 & 232 & 67 & 81 & $21 \%$ \\
\hline Z08 & $\mathrm{I}-65$ & 245 & 262 & 116 & 88 & $-24 \%$ \\
\hline Z09 & $\mathrm{I}-65$ & 218 & 242 & 78 & 35 & $-55 \%$ \\
\hline $\mathrm{Z} 10$ & $\mathrm{I}-74$ & 137 & 162 & 22 & 19 & $-14 \%$ \\
\hline Z11 & $\mathrm{I}-65$ & 45 & 73 & 71 & 91 & $28 \%$ \\
\hline Z12 & $\mathrm{I}-465$ & 0 & 12.5 & 156 & 129 & $-17 \%$ \\
\hline $\mathrm{Z} 13$ & $\mathrm{I}-465$ & 34 & 49 & 214 & 217 & $1 \%$ \\
\hline Z14 & I-65 & 101 & 110.5 & 107 & 121 & $13 \%$ \\
\hline Z15 & I-65 & 110.5 & 115.5 & 123 & 125 & $2 \%$ \\
\hline Z16 & I-70 & 78 & 94 & 165 & 169 & $2 \%$ \\
\hline Z17 & I-65 & 126 & 130 & 5 & 13 & $160 \%$ \\
\hline Z18 & $\mathrm{I}-65$ & 130 & 138 & 19 & 23 & $21 \%$ \\
\hline Z19 & I-865 & 0 & 5 & 20 & 16 & $-20 \%$ \\
\hline Z20 & I-465 & 20 & 25 & 52 & 54 & $4 \%$ \\
\hline Z21 & I-465 & 25 & 34 & 148 & 105 & $-29 \%$ \\
\hline Z22 & I-465 & 12.5 & 20 & 74 & 58 & $-22 \%$ \\
\hline \multirow[t]{2}{*}{ Z23 } & I-65 & 115.5 & 126 & 22 & 62 & $182 \%$ \\
\hline & & & Total & 1585 & 1547 & $-2.4 \%$ \\
\hline
\end{tabular}

23 work zones and assigns them a unique label that is used as a reference in the graphics that follow. Figure 1 shows statewide spatial distribution of 11 interstate work zones, while Fig. 2 shows a distribution of the remaining 12 interstate work zones that were concentrated in the Indianapolis metro area.

\section{Statewide Crash Data}

Crash data was aggregated from a review of all crashes in the study area. 5-mile approaches to each work zone wherever possible (both upstream and downstream) were also included in our analysis to account for tapers, transition areas, and merging resulting in crashes. In addition, impact on traffic from queuing resulting from construction activity in a work zone may potentially extend well beyond a work zone's extent thus underlining the need for including approaches in such an analysis. Owing to close proximity of work zones on interstate 465 , it was not feasible to include 5-mile approaches for the Z12, Z13, Z20, Z21, and Z22 work zones. To account for this, any gap (if existing) between pairs of adjacent work zones was split equally to create a lesser than 5-mile approach for both work zones. To prevent double counting of crashes on overlapping work zone approach extents, an open limit on the mile marker location for one work zone and a closed limit for the subsequent work zone were chosen. For example, hard-braking events and crash counts for $\mathrm{Z} 12$ were captured for $\mathrm{MM}>=0$ and $\mathrm{MM}<12.5$ while for $\mathrm{Z} 22$ were captured by $\mathrm{MM}>=12.5$ and $M M<20$. This procedure was then applied to all cases on I-465 and I-65 where work zone limits overlapped at a mile marker location to arrive at the crash counts shown in Table 1. Table 1 shows the total crash counts for both directions of each of the 23 construction work zones for the months of July and August in 2018 and 2019, along with percentage change in crash counts. Construction activities occurred in 2019 and crash data from the same 2 months in 2018 was used to visualize if a change in crash counts was seen between the two years owing to construction activity. An overall decrease of $2.4 \%$ in crash counts was seen over the 23 work zones for the 2-month analysis period. Comparing changes in crash counts for individual zones between 2018 and 2019, 13 work zones showed an increase in crash counts, 1 zone showed no change, and 9 zones showed a decrease in crash counts.

One of the major hurdles with using crash data as a performance measure for work zone safety is that crash reports often do not get filed in real time, some agencies still use 
Fig. 1 Statewide view of interstate work zone projects with approaches

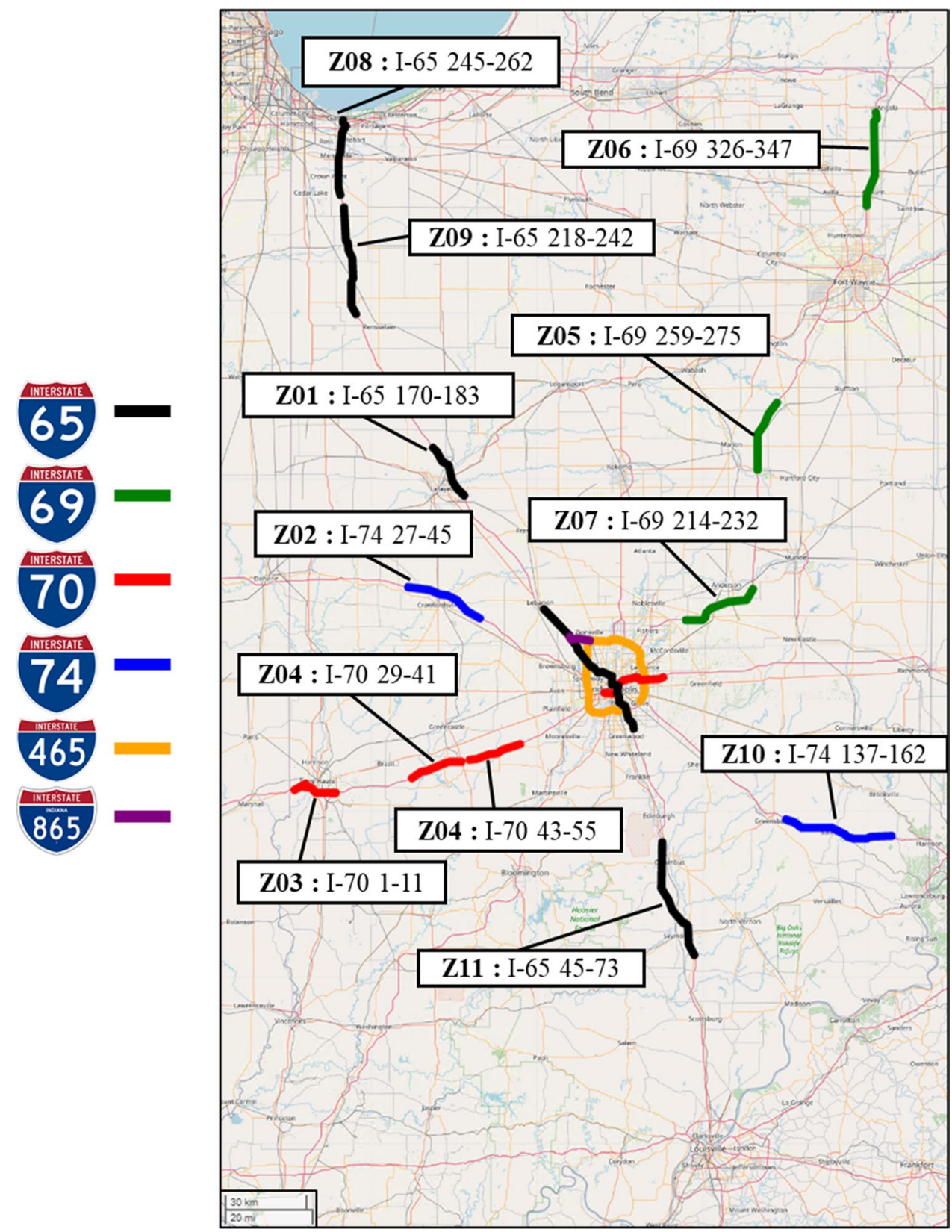

paper-based reporting methods, and serious crashes often require several days of investigation before reports are available online. On average, only $80 \%$ of the crash reports are available in a statewide database within 1 week of the crash and some crash reports take as long as 6 months to appear in the database. Thus, any real-time road safety analysis using aggregate collision counts will have an underrepresentation of crash data.

\section{Crash Count Comparisons}

For the period of July 1 to August 31 in 2018 and 2019, crash reports were obtained and individually mapped to the 23 work zones under consideration. Across all 23 work zones for the analysis period, 2018 saw 1585 crash incidents while 1547 crashes were seen for the corresponding period in 2019. Crash counts were normalized across work zones by dividing the total number of crashes occurring in a zone by the length of the zone calculated as the difference between the approach start and end mile markers as listed in Table 1. Figure 3 shows a sorted stacked column chart of normalized crash counts for the 23 work zones compared for the period of July 1 to August 31 for 2018 and 2019. Work zones are ordered from left to right in descending order of number of crashes per mile for 2019. Each column shows crash counts per mile categorized by 
Fig. 2 Indianapolis metro area view of interstate work zone projects with approaches
Fig. 3 Crash counts normalized by work zone length and categorized by severity for 23 work zones for July 1 to August 31 for 2018 and 2019 (highlighted work zones in red indicate work zones that showed an increase in crash count from 2018 to 2019)
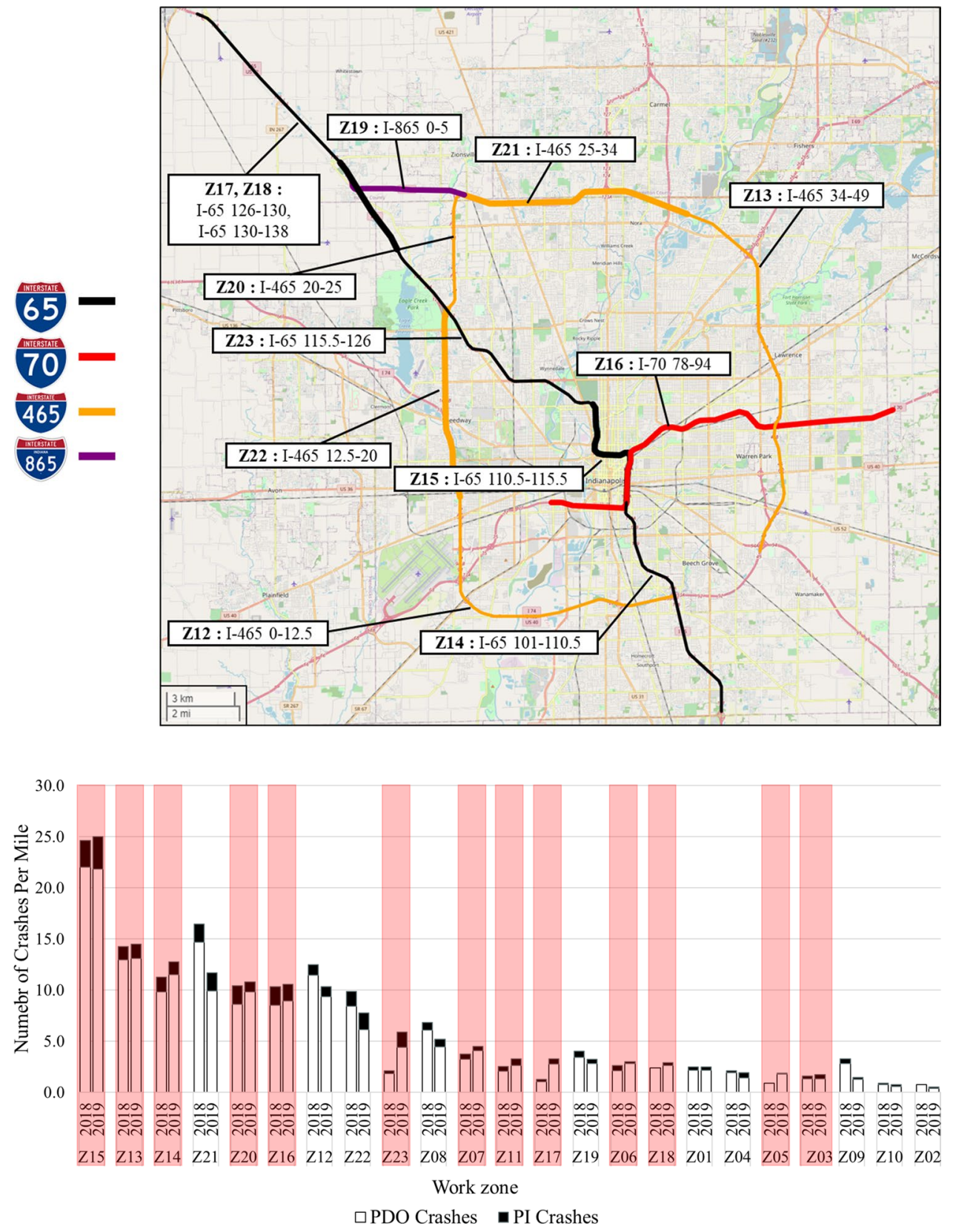

severity between property damage only (PDO) and personal injury (PI). Owing to small numbers of fatal crashes on interstates and for privacy reasons, personal injury and fatality data in this study is combined into and referenced by the PI category. In addition, it was observed that PI crashes only account for approximately $14 \%$ of the total number of observed crashes in this study. Segregating the analysis by crash severity category would not have resulted in a good sample for the PI category to arrive at reliable results. Hence, crashes from both categories (PDO and PI) were combined and the aggregate crash count per mile was used for each work zone for the analysis described in the sections that follow.
The work zone labelled Z15 which shows the highest crash per mile value for both years, covers a 5-mile stretch of I-65 that overlaps with I-70 near downtown Indianapolis. An average percentage change of $15.24 \%$ in crash counts from 2018 to 2019 was observed across all 23 work zones. Three work zones in particular showed far higher percentage change in crash counts than this average, namely Z23 (182\%), Z17 (160\%) and Z05 (114\%). Figure 3 highlights how the peak of the construction season resulted in an increase in crashes in most of the work zones. However, it is worth noting that 7 out of the 23 work zones (Z01, Z03, Z04, Z07, Z08, Z09 and Z11) witnessed construction activity in both years for the months of July and August. Although the 
comparison drawn here is not a direct comparison of active and inactive work zone periods, it is instrumental in underlining the need for an efficient safety performance analysis of work zones. The underlying assumption in making this assertion is that all other external factors (such as traffic volumes, weather conditions) remained the same from 2018 to 2019. Annual growth rate of Annual Average Daily Traffic (AADT) from 2018 to 2019 averaged over all 23 work zones in both directions of travel was found to be $-0.2 \%$. The months of July and August in total observed precipitation greater than 0.01 inches on 20 out of 62 days (32\%) in Central Indiana (home to 12 out of the 23 work zones) in both years (Central Indiana Local Climate Info, n.d.). The overall crash counts decreased by $2.4 \%$ for the 2-month period from 2018 to 2019. This decrease can be attributed to a number of factors including: improved early warning systems implemented by agencies and contractors for motorists, reduced vehicle volumes, underreporting and delayed reporting of crash incidents, a number of work zones that observed construction activity for both years may have resulted in learnings from 2018 contributing to better decision making and work zone design in 2019 resulting in lower crash counts.

\section{Statewide Hard-Braking Data}

As indicated in previous sections, there is considerable variation in the time and location of reported crashes, as well as delay in that data being available in a database. In contrast, modern connected vehicles can provide GPS location and accurate time stamps of hard-braking events. Hard braking is an event in which a driver applies more force than is typically needed to slow or stop a vehicle using the vehicle's brake system. For this study, crowdsourced hard-braking event data for the state of Indiana was made available wherein any deceleration of $8.76 \mathrm{ft} / \mathrm{s}^{2}$ or greater occurred.

For every hard-braking event, a geolocation, timestamp and speed value were provided to spatially and temporally map these events. Approximately 12.7 million unique hardbraking events were recorded throughout the state of Indiana for the period of July 1 to August 31, 2019. Figure 4 shows a statewide map summarizing spatial distribution of hardbraking event activity seen in Indiana during the months of July and August in 2019. Among these, more than 196,000 hard-braking events in total were found to have occurred over the 23 work zones as a result of spatial joins performed on the dataset to zero in on events occurring in 46 created geofences (one per direction of travel per work zone). AADT values for 2019 were compared with trip counts in each work zone for July 2019 to arrive at an average penetration of $4.7 \%$. The third-party crowdsourced hard-braking event data showed highest penetration rates for urban interstate work zones.
Fig. 4 Plot of 12.7 million hardbraking events in Indiana for July 1 to August 312019

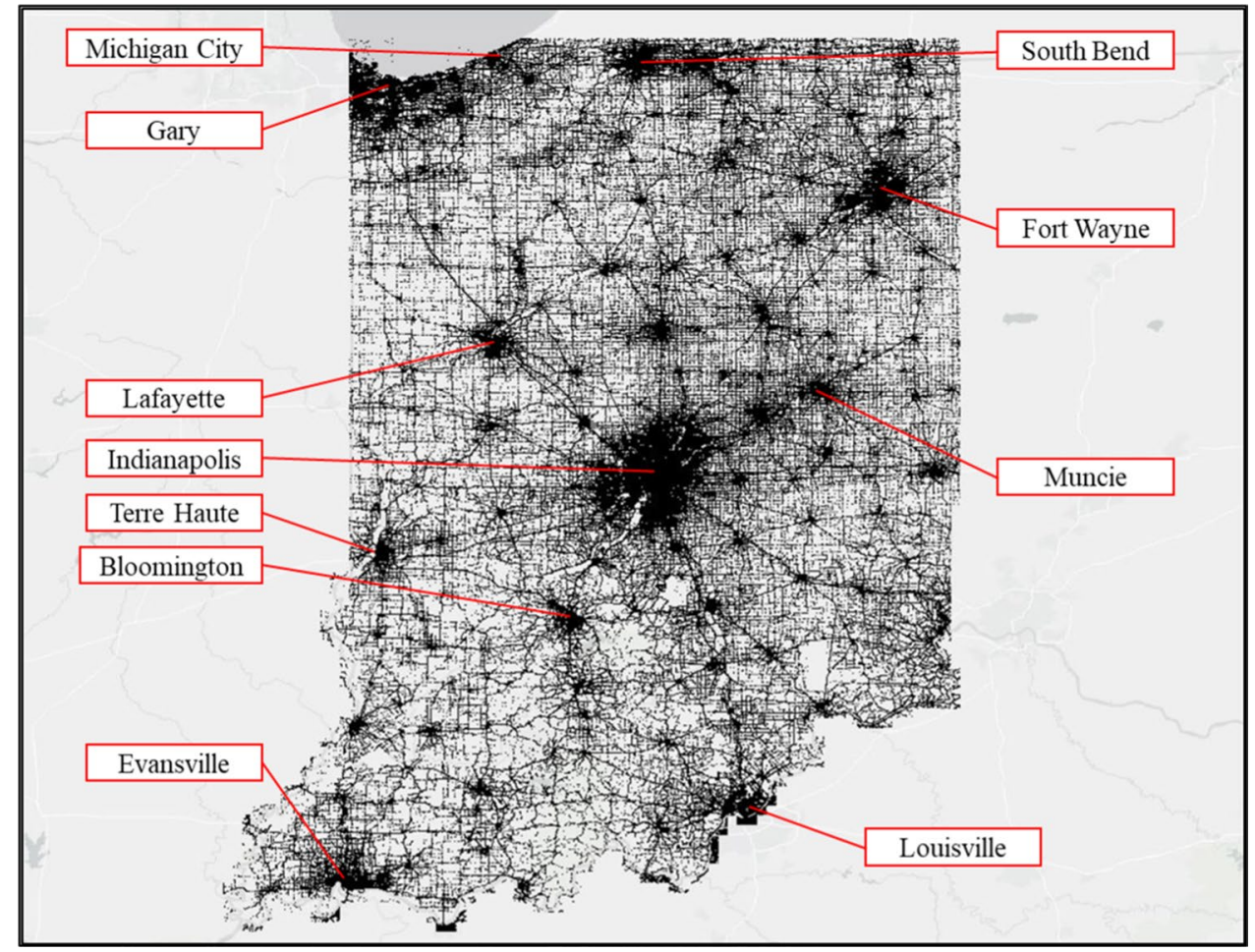




\section{Methodology}

\section{Capturing Hard-braking Event Counts by Work Zone and Direction of Travel}

Owing to the computational complexities involved in handling this large hard-braking dataset of 12.7 million events, matching each event individually to its nearest interstate location was infeasible. Similar hard-braking event counts available for the month of August 2020 for 11 states-California $(25,441,595)$, Connecticut $(2,048,510)$, Georgia $(8,704,155)$, Indiana $(6,683,366)$, Minnesota $(3,254,094)$, North Carolina $(6,546,877)$, Ohio $(10,012,453)$, Pennsylvania $(9,831,815)$, Texas $(26,300,993)$, Utah $(948,931)$ and Wisconsin $(4,049,073)$, underlined the need for a quicker procedure for capturing hard-braking activity at specific locations on roadways of interest. Owing to this, an alternate approach was developed wherein 46 separate geofences were created to spatially outline the area for every work zone analyzed in this study in two directions of travel. From the statewide dataset of hard-braking events shown in Fig. 4, spatial joins were then used to effectively narrow down the hardbraking dataset to events that occurred within the virtual perimeter defined by any of the 46 geofences mentioned earlier. A temporal join was next applied to this dataset to further narrow down the events to those that occurred within the period from July 1 to August 31, 2019. Callout (i) on Fig. 5 shows such a set of geofenced polygons capturing hard-braking events on I-65 in the northbound direction of travel in the vicinity of mile marker 102. Each hard-braking event represented by a colored dot on Fig. 5 has been colorized by the initial speed recorded in miles per hour at the time of hard braking. When this procedure was repeated individually 46 times for each work zone by
Fig. 5 Geofenced polygons showing hard-braking events colorized by initial speed in miles per hour on I-65 in the northbound direction of travel in the vicinity of mile marker 102

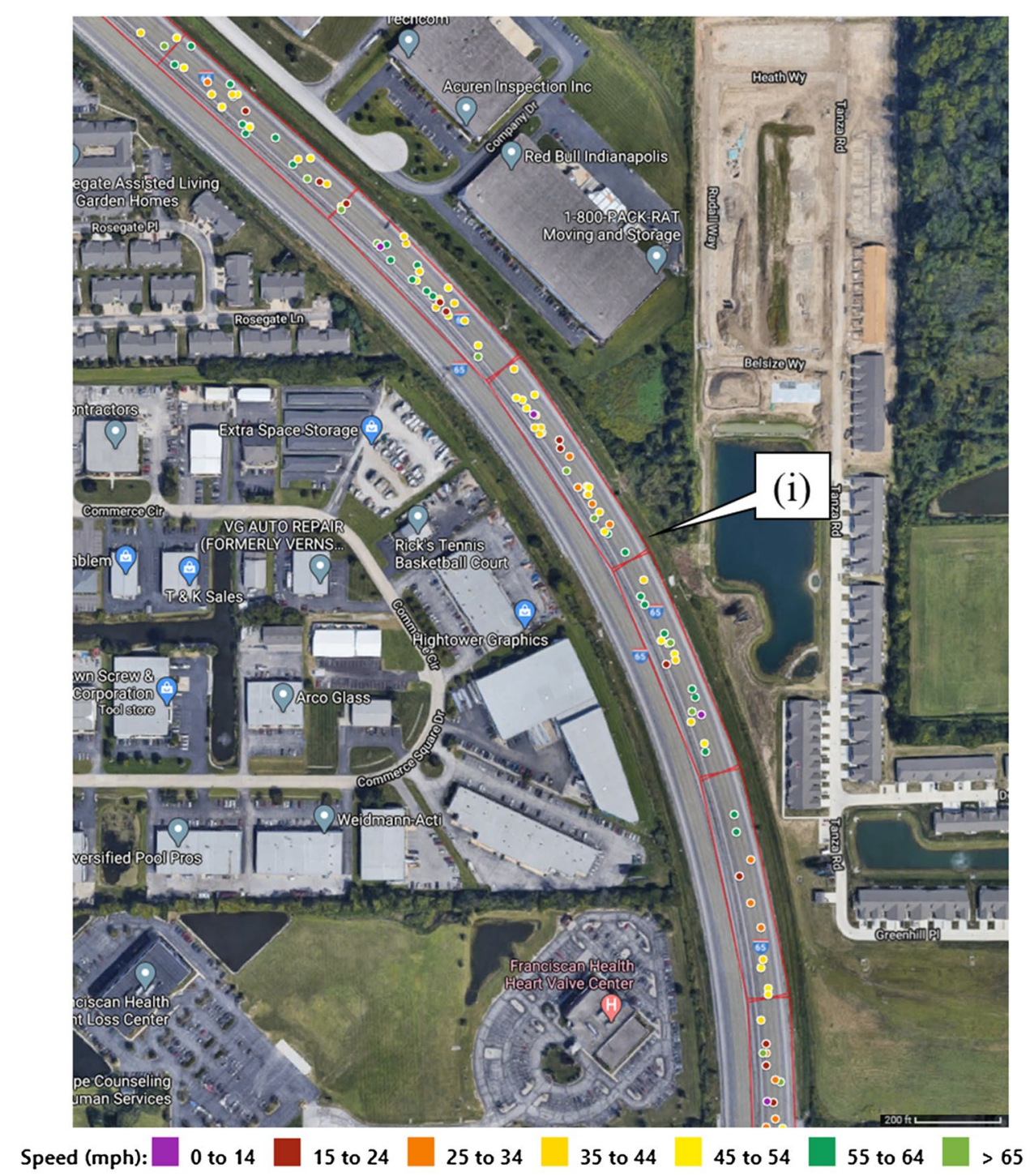


direction, the dataset of 12.7 million hard-braking events was narrowed down to the 196,215 hard-braking events used for the analysis in this study.

\section{Visualizing Relationship Between Congestion, Crashes, and Hard-Braking Events}

Figure 6a shows a spatial and temporal heatmap of traffic speeds for the period of July 1 to August 31, 2019 for a nine and a half mile stretch of I-65 northbound from MM

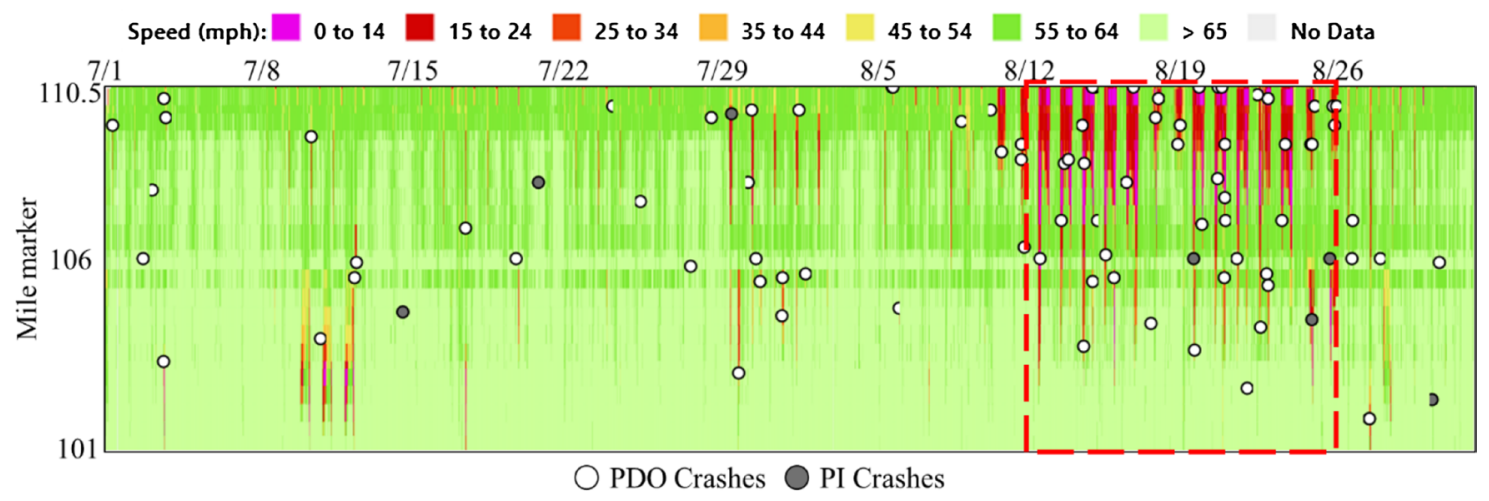

(a) Spatial-temporal heat map showing speed profiles by mile marker and day

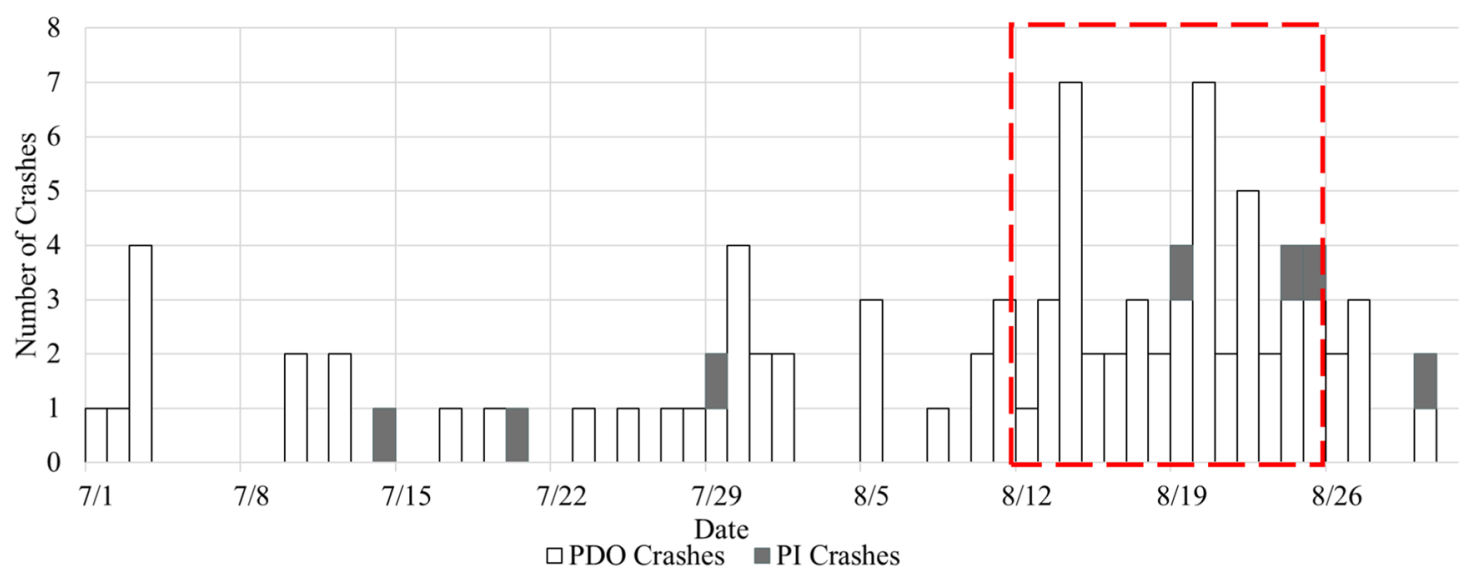

(b) Crash count column plots stacked by severity

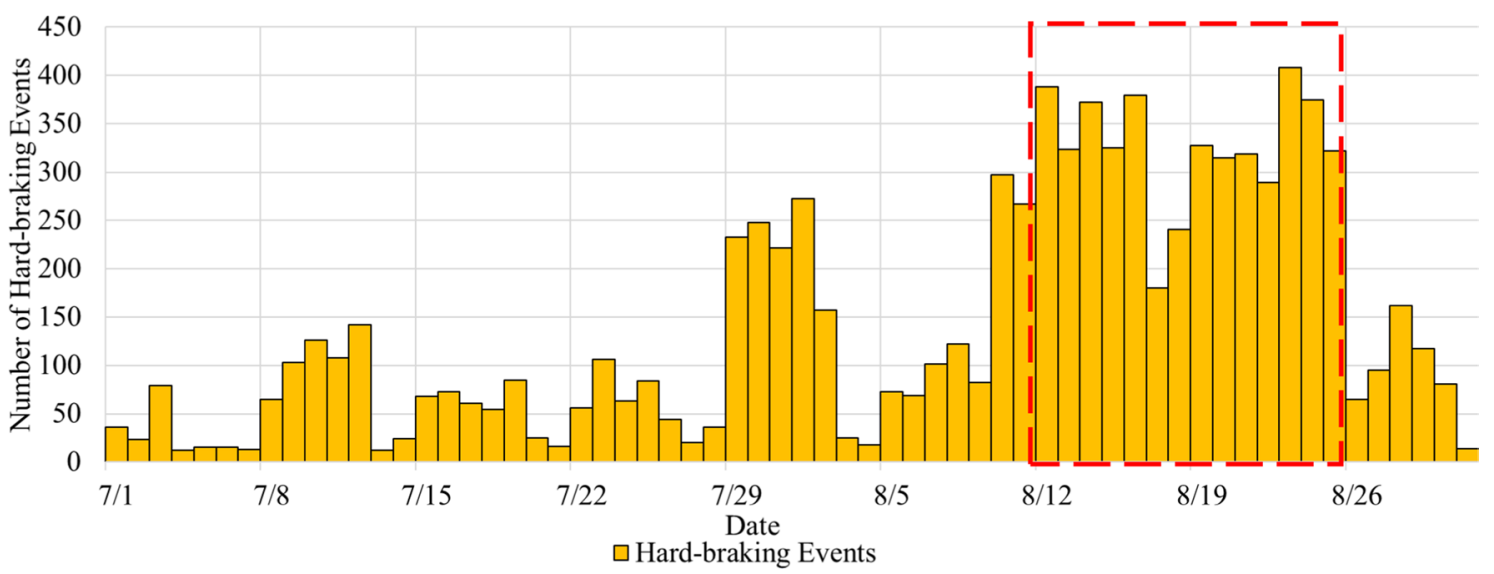

(c) Hard-braking events by day

Fig. 6 I-65 MM 101-110.5 in the northbound direction of travel from July 1 to August 31, 2019 
101-110.5. Work zone Z14 makes up the stretch of I-65 depicted in the heatmap in Fig. $6 \mathrm{a}$.

The legend at the top shows the color for speeds ranging from greater than $65 \mathrm{mph}$ (green) to less than $14 \mathrm{mph}$ (purple). The heatmap is generated from commercially available probe data consisting of average vehicle speeds for 1-mile interstate segments at 1 min fidelity ( $\mathrm{Li}$ et al. 2015). This visualization easily helps segregate recurring congestion from nonrecurring events as highlighted by red dashed lines in Fig. 6a. For the 2-week period beginning August 12,2019 , significant weekday recurring congestion can be seen between mile marker 106 and 110 (Work zone Z14) in the northbound direction of travel.

Crashes are shown on the heat map in Fig. 6a as circles. Property damage (PDO) crashes are indicated by hollow circles, while personal injury (PI) crashes are indicated by gray circles. Figure $6 \mathrm{~b}$ shows a stacked bar graph tabulation of the number of crashes occurring each day using the same color grey shading as the circles in Fig. 6a, with elevated crash counts for the 2-week period starting August 12, 2019 highlighted by red dashed lines.

Hard-braking event counts by day for this stretch of I-65 northbound are shown in Fig. $6 \mathrm{c}$ with the corresponding region of elevated crash counts and congestion highlighted by red dashed lines. It can clearly be seen from Fig. 6a, b, c how hard-braking activity clusters correspond to regions of elevated crash counts and congestion.

In this study, congested conditions are defined as lengths of interstate roadway that are operating below a speed threshold of 45 miles per hour (Brennan et al. 2013; Day et al., 2016). Long queues that often build up on interstate work zones, such as those highlighted by red dashed lines in Fig. 6a, would result in motorists having to swiftly slow down or hard-brake which increases the risk of a rear-end collision. Figure 7 shows the manner of collision percentages for the 92 crashes recorded for this work zone in Fig. 6b. From the congestion seen in the region of MM $106-110$ in Fig. 6a, significant hard-braking activity is seen to have occurred in this same region shown in Fig. 6c, some of which may have contributed to back-of-queue collisions. This is validated by the $49 \%$ of crashes occurring in the two-month period being rear end collisions shown in Fig. 7. Lane closures, lane shifts, crashes, sweeping and painting in work zones, and inclement weather are some of the leading causes that are expected to result in hard-braking activity as motorists adjust to changing roadway conditions.

In this particular instance, the region of heavy congestion and elevated crash counts was only able to be identified in an after-action review once crash reports were filed. Using hard-braking events as a surrogate for crash counts could have pinpointed this region of concern within $24 \mathrm{~h}$ instead of having to wait for a crash history to develop. This is visibly verifiable by the strong relationship observed between crash activity and hard-braking events in Fig. 6b, c.

\section{Evaluating Relationship Between Hard-braking and Crashes Within Work Zones}

Hard-braking events for each work zone occurring during July 1 to August 31, 2019 were totaled and divided by the extent of the work zone in miles (including approaches) to arrive at a value of hard-braking events per mile as shown below:
Fig. 7 Crashes by manner of collision percentages for Z14 in the northbound direction of travel, from July 1 to August 31,2019

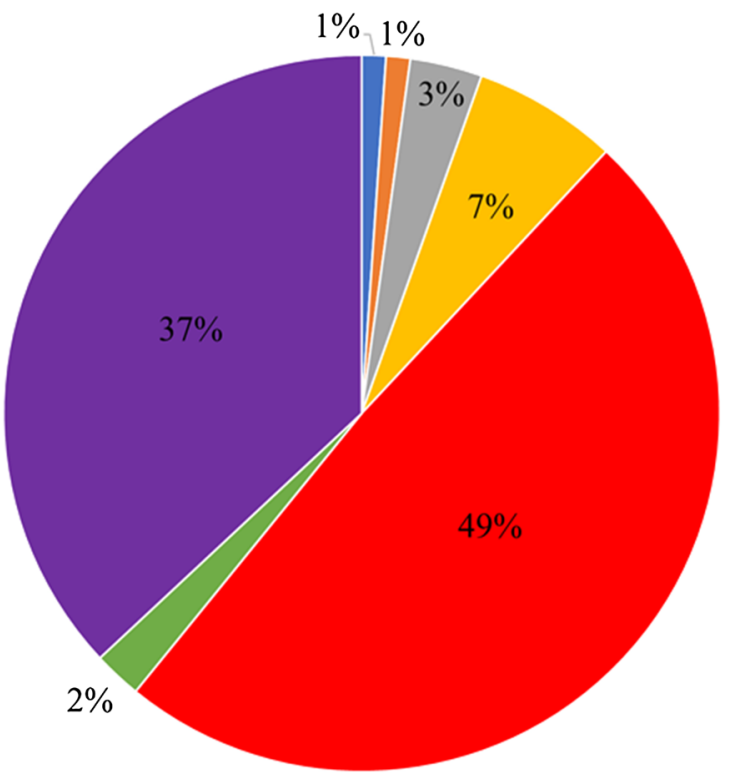

- Collision With Object in Road

- Head on between two motor vehicles

॥ Other/Unknown

= Ran Off Road

- Rear End

- Right Angle

- Same Direction Sideswipe 
Hard-braking Events $\quad$ Hard - braking Events July 2019 $_{19}+$ Hard - braking Events August 2019

mile $=\frac{\text { Approach End MM - Approach Start MM }}{2}$

Mile markers and directional information were used from statewide crash reports to spatially determine if a crash occurred within any of the 23 work zones' boundaries. The total 2-month crash count was then calculated and divided by the extent of the work zone in miles (including approaches) to similarly arrive at the crashes per mile value defined as:

$\frac{\text { Crashes }}{\text { mile }}=\frac{\text { Crashes }_{\text {July 2019 }}+\text { Crashes }_{\text {August } 2019}}{\text { Approach End MM - Approach Start MM }}$

These numerical quantities together form the basis for evaluating the relationship between hard-braking activity and crash occurrences.

Figure 8 shows a scatter plot of crashes per mile against hard-braking events per mile for each of the 23 work zones, calculated separately for each direction of travel, for data totaled over the 2 months of July and August in 2019. A linear trendline is plotted over the data points which returned an $R^{2}$ value of 0.85 . The plot shows that in general, 1 crash per mile is to be expected for approximately every 147 hard-braking events per mile within a work zone. With the exception of a few outliers visible in Fig. 8 , it can be safely said that crashes per mile increase at a steady rate with respect to hard-braking events per mile.
Our approach to determining the correlation between hardbraking event and crash incident counts involved the use of the linear regression method. The regression resulted in an adjusted $R^{2}$ value of 0.845 with a $p$ value of 0.000 (rounded to three decimal places) reinforcing the statistical significance of obtained results.

Using this established relationship between crashes per mile and hard-braking events per mile and having accomplished the first objective of this study, one of the 23 work zones needed to be chosen for a case study in order to look at causal factors for increased hard-braking activity, the second objective of this study. The availability of an independent dataset, namely a mobile LiDAR map of the pavement profiles in work zone Z11 made it an ideal candidate for further analysis. Secondly, work zone Z11 was an area that had observed construction activity both in 2018 and 2019 and saw a $28 \%$ increase in crash count in 2019 pointing to a cause of concern for INDOT. This led to a case study analysis of crashes and hard-braking activity in this work zone described in detail in the following section.

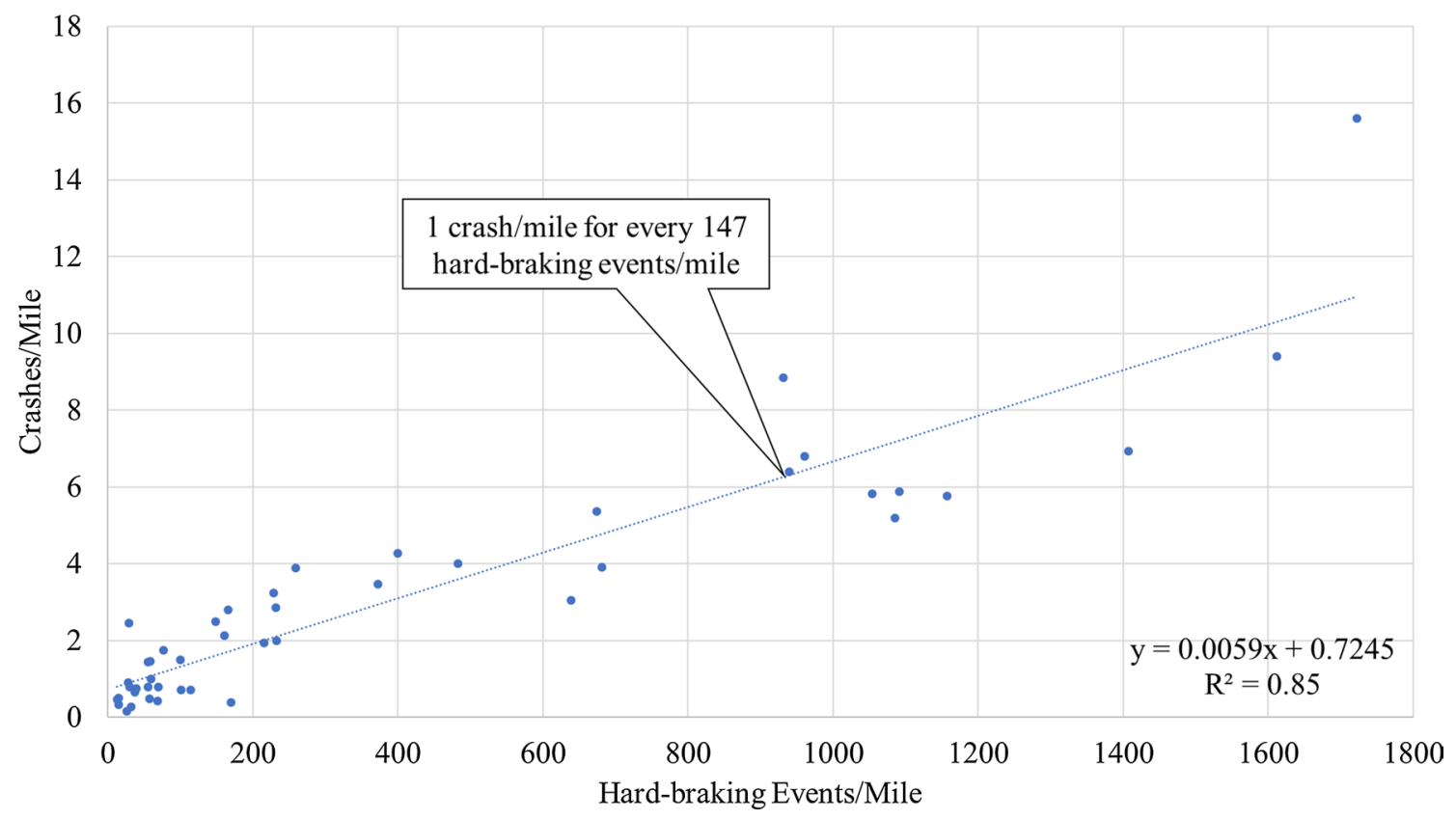

Fig. 8 Scatter plot showing crashes and hard-braking events per mile across all 23 work zones for July 1 through August 31, 2019 with a linear trendline 


\section{Results}

\section{Application Case Study: Work Zone Z11 (I-65 MM 50-68)}

As seen from Fig. 3 and Table 1, Zone 11 (Z11) experienced a modest increase in crashes and was representative of a common rural interstate construction work zone and there was a mobile LiDAR map available for detailed analysis during the time period. The northbound direction experienced approximately 70 hard-braking events/mile and 1.57 crashes per mile for the 2-month analysis period of July and August 2019. Figure 9 shows hard-braking event counts and

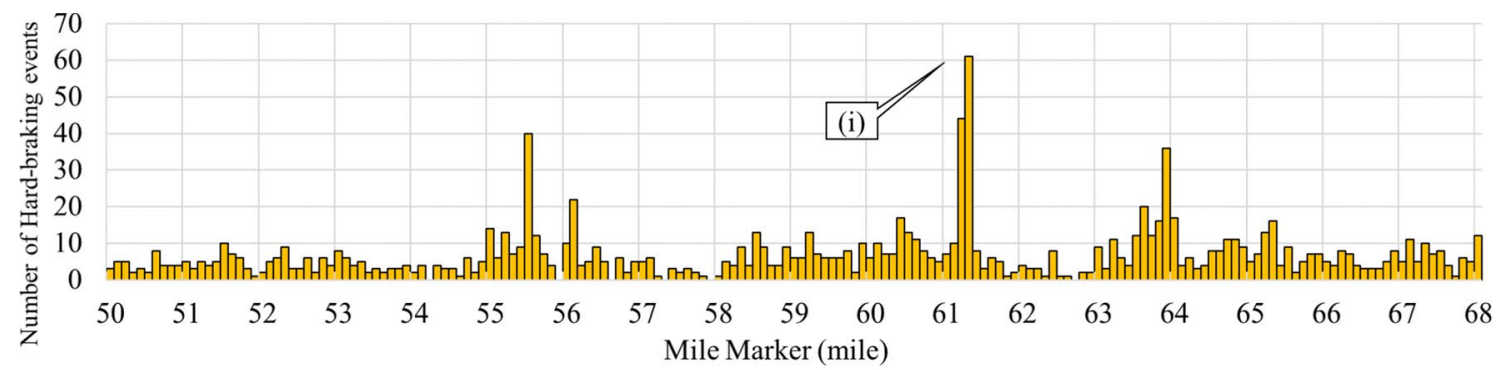

(a) Hard-braking events by tenth of a mile for July 1 through August 31, 2019

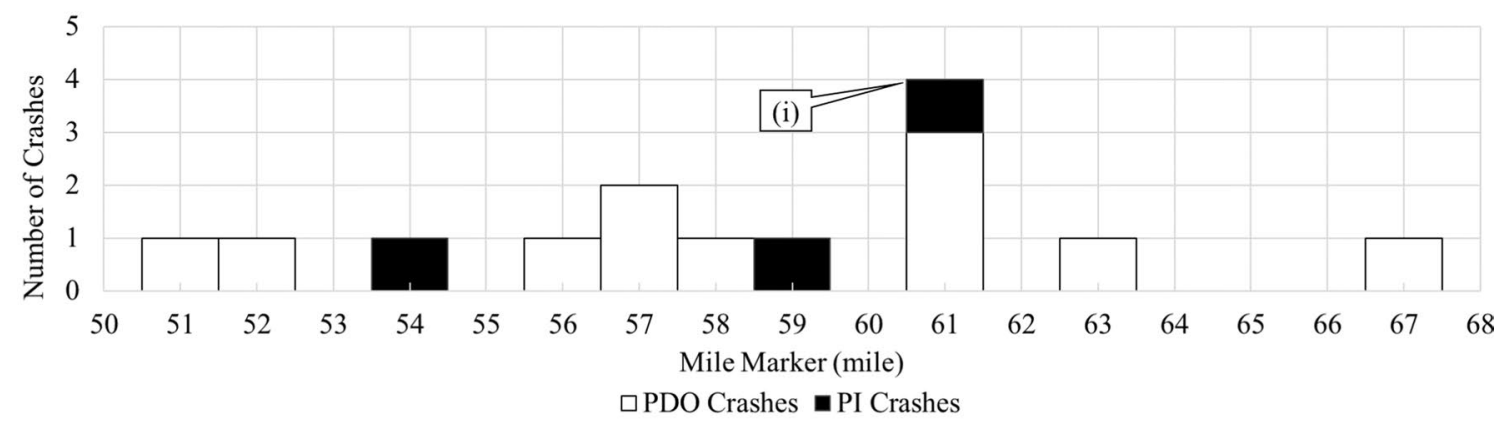

(b) Crashes by mile and severity, for July 1 through August 31, 2019

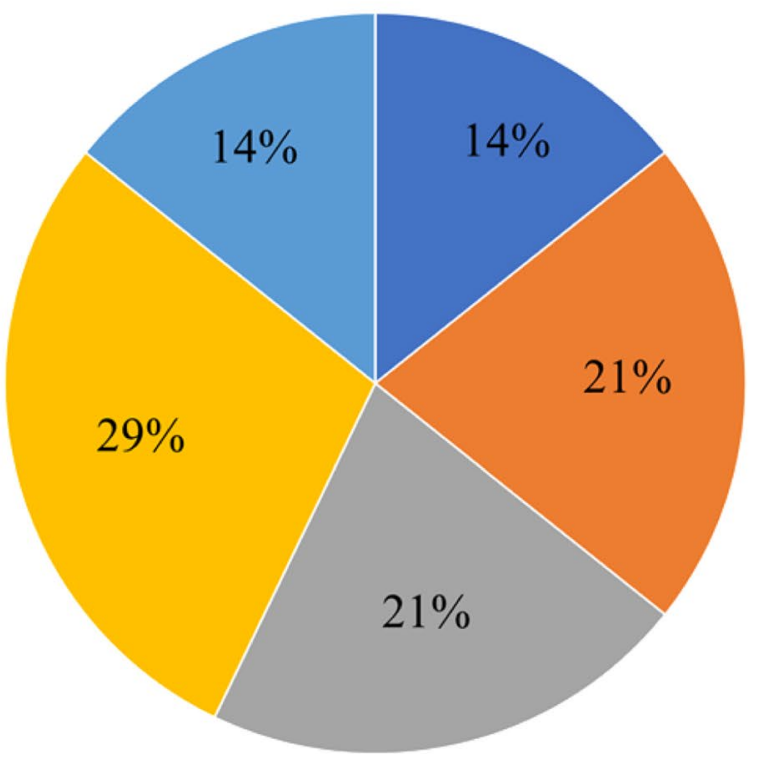

- Rear End

- Collision With

Object/Animal

- Same Direction

Sideswipe

- Ran Off Road

- Other

(c) Crashes by manner of collision percentages, for July 1 through August 31, 2019

Fig. 9 Northbound I65 Work zone Z11 (MM 50—68) 
crash counts for work zone Z11, categorized by severity and manner of collision, in the northbound direction of travel. Callouts (i) in Fig. 9a, b indicate an elevated frequency of crashes were in the vicinity of MM 61, the same region that exhibited an elevated number of hard-braking event counts. In fact, almost 60 hard-braking events within a 0.1-mile section of road in 2 months suggested an opportunity for further investigation.

To safely conduct this evaluation, a wheel-based mobile mapping system was used to capture images and lane width data in the vicinity of mile marker 61 on I-65 in the northbound direction on July 17, 2019 (M. M. Mekker et al., 2018a, b). Figure 10a and Fig. 11a show images collected using the mobile mapping system with cross sections of interest highlighted. Callouts (i), (ii) and (iii) in Fig. 10 and Fig. 11 correspond to the left, middle and right edges of traveling lanes used as reference points for lane width computations. Callout (i) has not been marked on Fig. 10a as the left edge line of the roadway was not visible in this particular image. Figure $10 \mathrm{~b}$ and Fig. $11 \mathrm{~b}$ show cross sectional pavement profiles colored by the intensity of LiDAR data aiding in feature visualization and specifically lane width measurement. A single cross-sectional pavement profile has been used in Fig. 10 to depict narrow lane widths. Two different cross-sectional pavement profiles are used in Fig. 11 to depict narrow lane widths (cross Sect. 1) and edge drop-offs (cross Sect. 2) separately. Figure 10b shows that at MM 61.196 the left lane and right lane have widths of $11.6 \mathrm{ft}$ and $10.6 \mathrm{ft}$ respectively. Figure $11 \mathrm{~b}$ similarly shows that at MM 61.262 the left and right lanes have lane widths of $11.8 \mathrm{ft}$ and $10.7 \mathrm{ft}$, respectively. The skid marks pointed to by callout (v) in Fig. 10a provide additional evidence of hard-braking events in this area. 14 crashes were observed on I-65 northbound between mile marker 50 and 68 for July 1 through August 31, 2019. Figure 9c shows the manner of collision for those crashes split into five distinct categories based on obtained crash reports namely-rear end, collision with object/animal, same direction sideswipe, ran off road
Fig. 10 I-65 northbound MM 61.196 as seen on July 17,2019

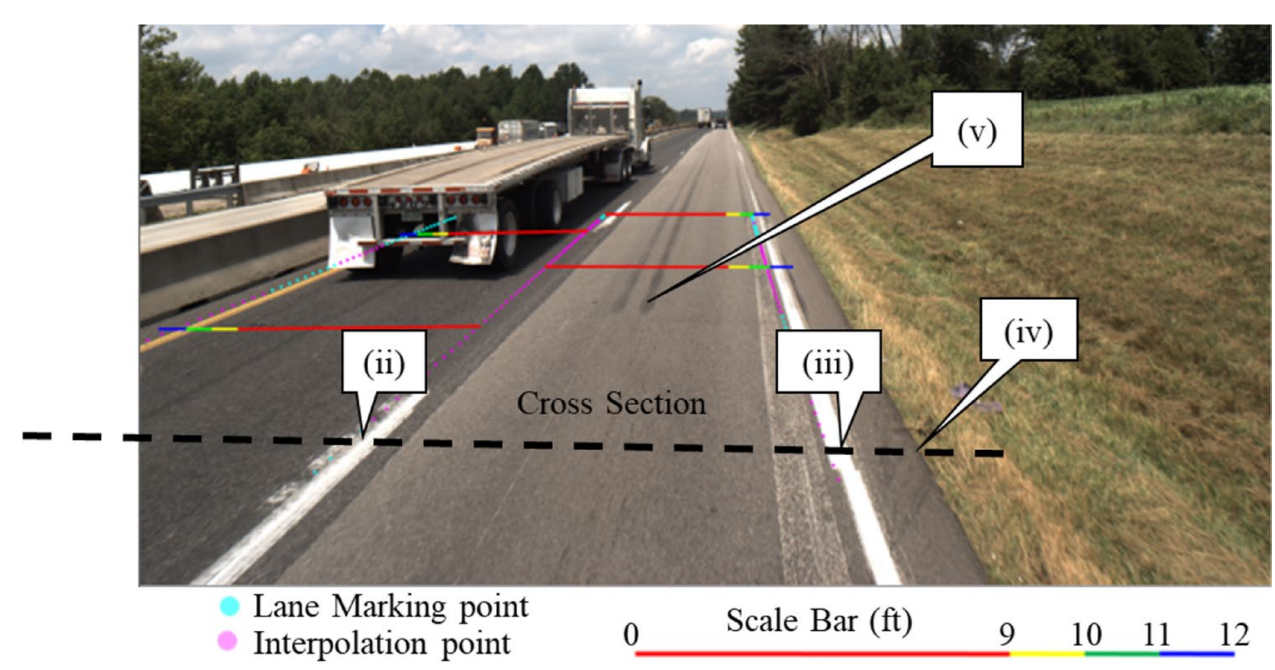

(a) Skid marks indicative of hard-braking activity

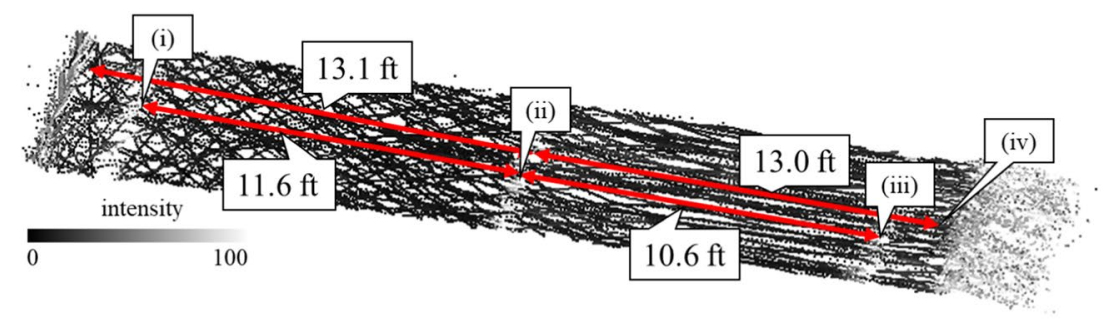

(b) Pavement profile at cross section colored by intensity showing lane widths

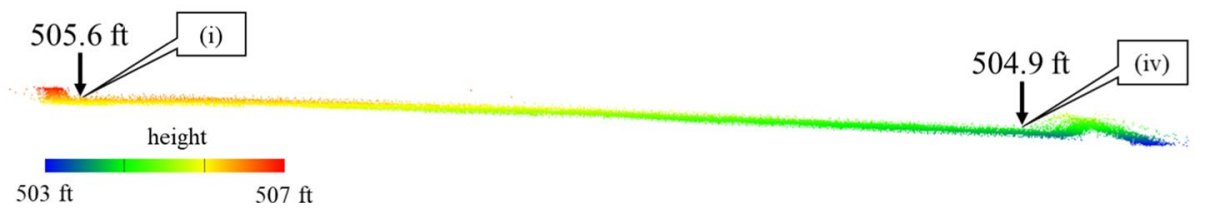

(c) Pavement profile at cross section colored by height 
Fig. 11 I-65 northbound MM 61.262 as seen on July 17, 2019

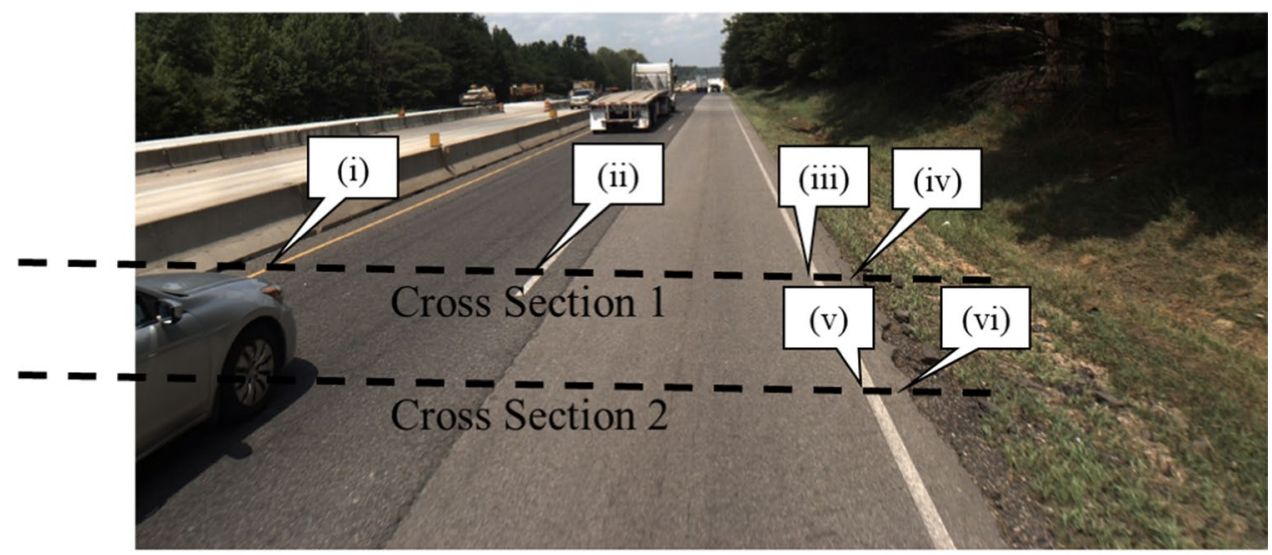

(a) Cross sections used to observe lane widths and edge drop-off

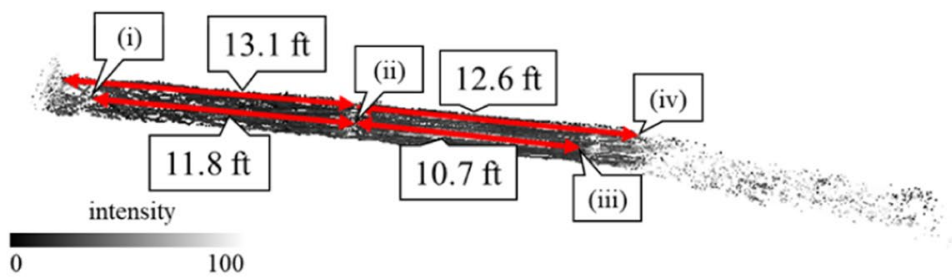

(b) Pavement profile at cross section 1 colored by intensity showing lane widths

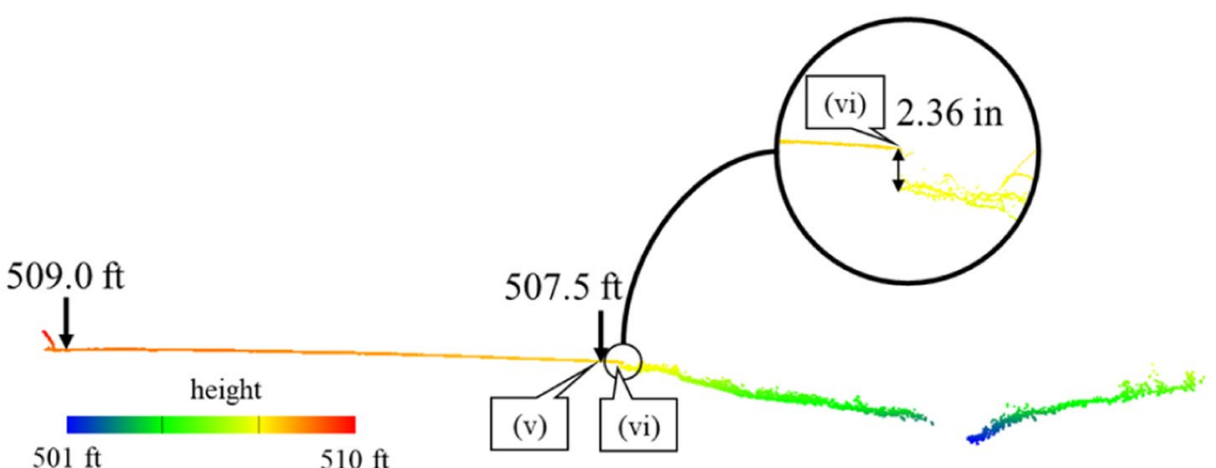

(c) Pavement profile at cross section 2 colored by height showing edge drop-off and other. $29 \%$ of the 14 crashes involved vehicles that ran off the road which points to a validation of the assertion that pavement edge drop-offs were a causal factor for crash incidents and hard-braking activity. The same direction sideswipes were the second leading manner of collision which points to narrow lane widths being a potential explanation as motorists would be forced to maintain far lesser lateral spacing when driving through the work zone resulting in a risk of sideswipes. Although the skid marks pointed to by callout (v) in Fig. 10a provide visual evidence of hard-braking activity, the $14 \%$ of crashes caused by a rear end collision provide further confirmation of the same.

Slightly further North, callout (vi) in Fig. 11a depicts broken pavement which results in the right edge line being 11.02 inches from the edge of pavement. Measurements in Fig. 11c using LiDAR data indicate an edge drop-off of
2.36 inches at the pavement boundary identified with callout (vi). Freeway design standards established by the American Association of State Highway and Transportation Officials (AASHTO) in 'A Policy on Geometric Design of Highways and Streets', more commonly referred to as the Green Book, state that through-traffic lanes on freeways must be $12 \mathrm{ft}$ wide (AASHTO 2001). This leads to the conclusion that observed lane widths in Fig. 10b and Fig. 11b are narrow lane widths. The combination of these narrow lanes and close proximity of a lane to the pavement edge provide a potential explanation for the high number of hard-braking events seen in this region on Fig. 9. 


\section{Conclusions}

This paper presented a quantitative analysis of hard-braking events and crash incidents conducted on 23 work zones across the state for a 2-month period that demonstrates the observed near-linear relationship between the two quantities. Image captures of skid marks, ambiguous lane markings and broken pavement resulting in edge drop-offs on one of the I-65 work zones in addition to LiDAR data were used to help validate high density of hard-braking events. This correlation helps to make the case for tracking hard-braking events in real-time which, when fused with traffic speeds, can aid in identifying opportunities for improvements in and around work zones. Use of hard-braking data can potentially help prioritize safety investments for agencies, without having to wait for crash history to develop over time on a stretch of road that is under evaluation. The study found that approximately 1 crash occurred for every 147 hard-braking events per mile with an average probe penetration of $4.7 \%$. Due to the challenge in accessing construction work zones for detailed measurements, mobile mapping technology is important for safely conducting measurement of lane widths and/or edge drop offs.

Some of the limitations of this analysis include the assumption of construction activities taking place in both directions of travel, inconsistencies with the reporting of crash locations and times, aggregate analysis conducted owing to unavailability of exact construction schedules and crash incident timestamps. Although this study only observed a set of 23 work zones to demonstrate feasibility, the methodology described herein can be easily scaled to a statewide level to monitor multiple work zones at a time due to the widespread availability of hard-braking event data.

Acknowledgements This work was supported by the Joint Transportation Research Program. Hard-braking event data for the period of July 1 to August 31,2019, used in this study, was provided by Wejo, Data Services, Inc. Probe vehicle speed data was provided by INRIX. The contents of this paper reflect the views of the authors, who are responsible for the facts and accuracy of the data presented herein, and do not necessarily reflect the official views or policies of the sponsoring organizations or data vendors. These contents do not constitute a standard, specification, or regulation.

Author contributions The authors confirm contribution to the paper as follows: (a) study conception and design: HL JKM, JD, DMB. (b) data collection: HL, JKM, JD, Y-TC. (c) analysis and interpretation of results: HL, JKM, JD, Y-TC, AH, DMB. (d) draft manuscript preparation: HL, JKM, JD, Y-TC, AH, DMB.

Funding The authors disclose receipt of the following financial support for the research, authorship, and/or publication of this article: This work was supported by the Joint Transportation Research Program and the Indiana Department of Transportation.
Data Availability The data that support the findings of this study are available from the corresponding author, Jairaj Desai, upon reasonable request.

Code Availability Not applicable.

\section{Compliance with Ethical Standards}

Conflicts of Interest The authors declare no potential conflicts of interest with respect to the research, authorship, and/or publication of this article.

Open Access This article is licensed under a Creative Commons Attribution 4.0 International License, which permits use, sharing, adaptation, distribution and reproduction in any medium or format, as long as you give appropriate credit to the original author(s) and the source, provide a link to the Creative Commons licence, and indicate if changes were made. The images or other third party material in this article are included in the article's Creative Commons licence, unless indicated otherwise in a credit line to the material. If material is not included in the article's Creative Commons licence and your intended use is not permitted by statutory regulation or exceeds the permitted use, you will need to obtain permission directly from the copyright holder. To view a copy of this licence, visit http://creativecommons.org/licenses/by/4.0/.

\section{References}

AASHTO (2001) Policy on geometric design of highways and streets, vol 1, no. 990. American Association of State Highway and Transportation Officials, Washington, DC, p 158

Blincoe L, Seay A, Zaloshnja E, Miller T, Romano E, Luchter S, Spicer R (2002) The Economic Impact of Motor Vehicle Crashes, 2000 6. Performing Organization Code NHTSA Technical Report None None. www.ntis.gov

Brennan TM, Remias SM, Grimmer GM, Horton DK, Cox ED, Bullock DM (2013) Probe vehicle-based statewide mobility performance measures for decision makers. Transportation Research Record: Journal of the Transportation Research Board. https:// doi.org/10.3141/2338-09

Central Indiana Local Climate Info. (n.d.). Retrieved October 23, 2020 , from https://www.weather.gov/ind/localcli

Davis GA, Hourdos J, Xiong H, Chatterjee I (2011) Outline for a causal model of traffic conflicts and crashes. Accid Anal Prev 43(6):1907-1919. https://doi.org/10.1016/j.aap.2011.05.001

Day C, McNamara M, Li H, Sakhare R, Desai J, Cox E, Horton D, Bullock D (2016) 2015 Indiana Mobility Report and Performance Measure Dashboards. https://doi.org/10.5703/1288284316352

FHWA (2018) FHWA Work Zone Facts and Statistics - FHWA Office of Operations. https://ops.fhwa.dot.gov/wz/resources/facts_stats .htm

Haque MM, Washington S (2015) The impact of mobile phone distraction on the braking behaviour of young drivers: a hazardbased duration model. Trans Res Part C 50:13-27. https://doi. org/10.1016/j.trc.2014.07.011

Haseman RJ, Wasson JS, Bullock DM (2010) Real-time measurement of travel time delay in work zones and evaluation metrics using bluetooth probe tracking. Trans Res Record 2169(1):40-53. https ://doi.org/10.3141/2169-05

Janstrup KH, Kaplan S, Hels T, Lauritsen J, Prato CG (2016) Understanding traffic crash under-reporting: Linking police and medical records to individual and crash characteristics. Traffic 
Injury Prevention 17(6):580-584. https://doi.org/10.1080/15389 588.2015.1128533

Jun G, Ogle J, Guensler R (2007) Relationships between crash involvement and temporal-spatial driving behavior activity patterns: use of data for vehicles with global positioning systems. Transp Res Rec 2019:246-255. https://doi.org/10.3141/2019-29

Kamla J, Parry T, Dawson A (2019) Analysing truck harsh braking incidents to study roundabout accident risk. Accid Anal Prev 122:365-377. https://doi.org/10.1016/j.aap.2018.04.031

Kiefer RJ, Leblanc DJ, Flannagan CA (2005) Developing an inverse time-to-collision crash alert timing approach based on drivers' last-second braking and steering judgments. Accid Anal Prev 37(2):295-303. https://doi.org/10.1016/j.aap.2004.09.003

Li H, Remias SM, Day CM, Mekker MM, Sturdevant JR, Bullock DM (2015) Shock wave boundary identification using cloudbased probe data. Trans Res Record 2526(1):51-60. https://doi. org/10.3141/2526-06

Li Y, Bai Y (2008) Development of crash-severity-index models for the measurement of work zone risk levels. Accid Anal Prev 40(5):1724-1731. https://doi.org/10.1016/j.aap.2008.06.012

Mekker M, Li H, McGregor J, Kachler M, Bullock D (2018) Implementation of a real-time data driven system to provide queue alerts to stakeholders. In: IEEE conference on intelligent transportation systems, proceedings, ITSC, 2018-March, 1-6. https:// doi.org/10.1109/ITSC.2017.8317648

Mekker MM, Lin Y-J, Elbahnasawy MKI, Shamseldin TSA, Li H, Habib AF, Bullock DM (2018) Application of LiDAR and connected vehicle data to evaluate the impact of work zone geometry on freeway traffic operations. Trans Res Record 2672(16):113. https://doi.org/10.1177/0361198118758050

Mollicone D, Kan K, Mott C, Bartels R, Bruneau S, van Wollen M, Sparrow AR, Van Dongen HPA (2019) Predicting performance and safety based on driver fatigue. Accid Anal Prev 126:142-145. https://doi.org/10.1016/j.aap.2018.03.004

Musicant O, Bar-Gera H, Schechtman E (2010) Electronic records of undesirable driving events. Trans Res Part F 13(2):71-79. https ://doi.org/10.1016/j.trf.2009.11.001

Tarko A (2019) Measuring road safety with surrogate events. Elsevier.

Tarko AP (2012) Use of crash surrogates and exceedance statistics to estimate road safety. Accid Anal Prev 45:230-240. https://doi. org/10.1016/j.aap.2011.07.008

Ullman G, Lomax T, Scriba T (2011) A primer on work zone safety and mobility performance measurement. Report, September 2011. https://trid.trb.org/view.aspx?id=1123390

Yamamoto T, Hashiji J, Shankar VN (2008) Underreporting in traffic accident data, bias in parameters and the structure of injury severity models. Accid Anal Prev 40(4):1320-1329. https://doi. org/10.1016/j.aap.2007.10.016

Publisher's Note Springer Nature remains neutral with regard to jurisdictional claims in published maps and institutional affiliations. 